\title{
Siemens Healthineers - A Risk Assessment
}

\section{Frederic Florian Hans-Joachim Fiedler*}

Department of Economics, TU Dresden, Germany

\begin{abstract}
In an increasingly complex world assurance and management control rises up on the agenda with its importance. This work is meant to analyze the existing risks for Siemens Healthineers. In this context COSO ERM integrated framework plays a role. The author concludes that Siemens Healthineer's risk exposition is quite favorable for the company.
\end{abstract}

Keywords: Management; Risk management; Medical; Data; Medical imaging; Diagnostics; Engineering; Business; Capital; Cost

\section{Introduction}

Siemens Healthineers is a subsidiary of German Siemens conglomerate for providing medical products and services. It accounts for approximately $1 / 9$ of the company's revenue and hence takes a major role in the risk management of the company. A close look on the risk management of Siemens Healthineers gives valuable insight on how reliable the medical pillar can sustainably contribute to the company's overall performance.

The risk assessment is performed with state-of-the-art methods by analyzing publicly available data provided by Siemens AG and further sources.

As Siemens Healthineers has rigorously implemented COSO ERM integrated framework and after analyzing the given data the author concludes, that Siemens Healthineers risk management approach suffices to the contemporary risk management standards.

\section{Overview of Siemens AG}

Siemens Healthineers is a separately managed subsidiary of the German Siemens conglomerate active in the field of medical products and services including medical imaging, laboratory diagnostics, pointof-care testing, healthcare IT and infrastructure and services [1]. The cornerstone of what would later become Siemens AG was laid by Werner von Siemens and Johann Georg Halske in 1847 in Berlin when they founded Siemens \& Halske, a company developing and producing telegraph poles. Subsequent mergers with Siemens-Schnuckertwerke in 1903 and Siemens-Reiniger-Werke in 1932 created the company known today as Siemens AG, one of the world's leading engineering companies in the areas of power generation, power transmission and medical diagnosis [1]. Headquartered in Munich and Berlin, the company employs about 348000 employees worldwide and generates sales of approximately $€ 85.51$ bil with a market capitalization of $€ 91.8$ bil [2]. Siemens AG is subdivided in the business units of power and gas, wind power and renewables, energy management, building technologies, mobility, digital factory, process industries and drives, financial services and healthcare. While the former businesses are managed under the Siemens AG conglomerate, Siemens Healthineers is managed separately as "a company within a company" to enjoy greater freedom in its market development, strategic direction and resource allocation to be able to better react to changes in the external environment [3].

\section{Healthineers}

Siemens Healthineers is one of the biggest suppliers of medtech infrastructure worldwide. Currently, it has a direct presence in 75 countries worldwide with more than 46000 employees and sales revenues of approximately $€ 13$ bil. Healthineers is one of the major players in the field of medical equipment and services with more than $70 \%$ of critical clinical decisions being influenced by the type of technology provided by Siemens Healthineers [4].

\section{Strategic Objectives}

To remain a viable competitor, engineering excellence and innovativeness is paramount in the fields of medical imaging, engineering and diagnostics. Strategically, Siemens Healthineers focuses on helping healthcare providers, its customers, to increase efficiency and reduce costs through the development of new and innovative product solutions. These strategic objectives are also reflected in its newly introduced name "Healthineers" which incorporates the ideas of "engineering success" and "pioneering in healthcare" [5]. However, the achievement of the strategic objectives is highly dependent on the success of the company's' risk management practices regarding risks stemming from its internal and external environment.

\section{Siemens Healthineers Risk Management Approach}

Siemens and Siemens Healthineers' risk management policies focus on managing appropriate risks and avoiding inappropriate threats while simultaneously pursuing sustainable growth and creating economic value. The company has established an enterprise-wide process for strategic planning and management reporting to assist in considering potential risks. Siemens' enterprise risk management approach is based on the integrated risk management framework developed by COSO in 2004. This framework connects the ERM process with the financial reporting and internal control system. Additionally, the risk management approach is based on a net risk approach indicating that risks, threats and opportunities are addressed after the execution of appropriate risk management practices. Usually, risks and opportunities are evaluated and reported on a quarterly basis at Siemens. Relevant risks are then prioritized in terms of impact and

${ }^{*}$ Corresponding author: Frederic Florian Hans-Joachim Fiedler, Department of Economics, TU Dresden, Wittenberger Str. 64, Dresden, Saxony 01309, Germany, Tel: +4917624700201; E-mail: frederic.fiedler@mailbox.tu-dresden.de

Received July 20, 2018; Accepted August 20, 2018; Published August 24, 2018

Citation: Fiedler FFH-J (2018) Siemens Healthineers - A Risk Assessment. J Account Mark 7: 290. doi: 10.4172/2168-9601.1000290

Copyright: (C) 2018 Fiedler FFH-J. This is an open-access article distributed under the terms of the Creative Commons Attribution License, which permits unrestricted use, distribution, and reproduction in any medium, provided the original author and source are credited. 
likelihood. Bottom-up workshops with the respective managers help to further identify potential actions to deal with these risks. The risk management process is overseen by the Risk Management and Internal Control Organization headed by the Chief Risk \& Internal Control Officer and the Corporate Risk and Internal Control Committee.

\section{Risks from internal weaknesses}

Risks emanating from internal weaknesses can be detrimental to the company's' operational and financial success. Common internal weaknesses often include the absence of important skills, insufficient or poorly working internal controls, poor product or service quality leading to dissatisfied customers or low employee satisfaction levels which may lead to poor employee performance.

Skilled labor: In the fields of medical imaging and diagnostics, innovativeness is one of the key factors for success. To achieve this objective, Siemens Healthineers spends, on average, more than $€ 1$ bil on research and development activities annually which has already led to 12500 granted patents globally [4]. However, the success, performance and usefulness of its innovations is highly dependent on the skill levels of its employees. Currently, competition for highly skilled personnel in the industry such as specialists, experts and "digital" talents is intense. Thus, the attraction, development and retention of qualified personnel is paramount. To deal with this risk, the company places great importance on structured succession planning, training opportunities for all employees, retention and career management and employer branding to become an employer of choice [4]. The company has established the "Siemens Learning Campus" which offers all employees the opportunity for broadening their skills and advance their careers [6].

Employee satisfaction: One major risk stemming from the internal environment concerns employee job satisfaction levels. It is well established among practitioners and academics that increases in job satisfaction lead to increases in job performance [7]. While there is a range of demographic variables that influence job satisfaction levels, one of the major determinants is an adequately perceived work-life balance [8]. Siemens places great importance on enabling its employees to create a workplace that satisfies this need by offering a work environment with flexible work conditions and programs such as childcare provision, re-entry programs after parental leave, flexible working schedules and home office arrangements [9]. The efforts appear to be paying out; in Canada, for example, Siemens was voted as one of the best companies to work for in 2016 [2]. Further proof of employee satisfaction can be found in the fact that around $50 \%$ of Healthineers' employees worldwide have been with the company for more than 10 years. Similarly, $92 \%$ of employees indicate that they are willing to "go the extra mile" for the company [10].

Loss of efficiency and effectiveness due to cross-cultural differences: Being a multinational company also entails the challenge of facing cross-cultural differences that need to be managed appropriately to achieve operational efficiency and effectiveness. The mismanagement of cross-cultural differences can have a disastrous effect on the operational and financial performance of a company. Cooper [11] was among the first researchers to investigate the effect of cross-cultural values and differences on work-outcomes in his studies at IBM. Subsequent research by the author validates his findings that cross-cultural differences, perceptions and values can have a major impact on communication efficiency and effectiveness and thus on firm performance. To create a better understanding of cross-cultural differences, Siemens encourages the development of an international mindset through, for example, the targeted exchange of employees abroad [10].

Mergers and acquisitions, joint ventures and strategic alliances: Part of Siemens' strategy includes the expansion of business through mergers and acquisitions, strategic alliances or joint-ventures. These activities are inherently risky since difficulties may arise when trying to integrate people, operations, technologies or products. Additionally, when entering joint-ventures or strategic alliances, the company is usually unable to influence corporate governance processes or business decisions taken by the partner. If the partner should engage in any illegal, fraudulent or reputation damaging activities, this may also transfer to Siemens. To deal with this risk, Siemens has introduced standardized processes, dedicated roles and responsibilities in areas of mergers and acquisitions and claim management.

Weak internal controls: Well-functioning internal controls are important for ensuring operational effectiveness and efficiency to achieve organizational goals and objectives. Moreover, the opportunities for fraudulent activities can be decreased greatly and adherence to international auditing rules and regulations can improve the company image. Siemens makes use of the COSO enterprise risk management (ERM) framework to connect its ERM processes to its financial reporting and internal control processes. This integrative approach ensures a concise and complete view of the company. The importance of internal controls is also reflected in the Risk Management and Internal Control Organization, headed by the Chief Risk and Internal Control Officer and the Corporate Risk and Internal Control Committee, established by the Managing Board. The internal control system is based on the internal control integrated framework developed by COSO. The controls and control systems are evaluated each fiscal year regarding their design and operating effectiveness. To do so, standardized procedures are used to define the necessary controls, document them according to uniform standards and tested regularly by management. Additionally, the audit committee and the internal auditor evaluate the internal control system regularly to ensure its adherence to the company's compliance policies and effectiveness of internal controls [5].

Risks from external threats: As any public or private organization, Siemens Healthineers is exposed to threats from its external environment. Neglecting the development of appropriate risk management strategies can result in substantial yet avoidable financial losses and going concern issues.

Economy: The general economic state can have a major impact on any business's performance. Generally, being in the healthcare industry, Siemens Healthineers does not suffer from major changes in customer demand due to changes in customer preferences. Changes in population demographics can be interpreted as rather favorable for the healthcare industry due to an aging population and thus growing demand for healthcare products and services. Additionally, as a globally working company, Healthineers can offset weaknesses in certain geographic areas with growth in other areas. In 2016, Latin American Operations reported only a very weak performance due to the economic recession in this part of the world. However, stabilizing growth of the Chinese operations and moderate growth in the US and Europe could offset these losses [4]. Moreover, a large part of the company's revenue stems from recurring business so that the business activities are to a certain extent resilient to short-term economic trends.

Government laws and regulations: In the healthcare industry, companies are subject to a series of government and public regulations 


\begin{tabular}{|c|c|c|}
\hline Risk & Source & Action \\
\hline Attraction and retention of qualified personnel & Internal & $\begin{array}{l}\text { - Structured succession planning } \\
\text { - Retention and career development } \\
\text { - Training opportunities } \\
\text { - Employer branding }\end{array}$ \\
\hline Employee job satisfaction levels & Internal & $\begin{array}{l}\text { - Work-life balance } \\
\text { - Flexible working hours } \\
\text { - Re-entry programs after parental leave } \\
\text { - Childcare }\end{array}$ \\
\hline Cross-cultural differences & Internal & - Exchange programs of employees \\
\hline $\begin{array}{l}\text { Reputational or financial damages resulting } \\
\text { from M\&A, Joint Ventures, strategic alliances }\end{array}$ & Internal & $\begin{array}{l}\text { - Standardized processes } \\
\text { - Dedicated roles and responsibilities } \\
\text { - Claim management }\end{array}$ \\
\hline Weak internal controls & Internal & $\begin{array}{l}\text { - Audit Committee } \\
\text { - Regular evaluation and review of internal controls by management and internal } \\
\text { auditor } \\
\text { - Standardized procedures and uniform standards for evaluating internal controls } \\
\text { - Internal Control Officer and Corporate Risk and Internal Control Committee }\end{array}$ \\
\hline Economic state & External & - Diversification through multinational operations \\
\hline $\begin{array}{l}\text { Failure to adhere to governmental regulations } \\
\text { and policies }\end{array}$ & External & $\begin{array}{l}\text { - Use of quality management tools } \\
\text { - Use of measure of quality improvement and claim prevention }\end{array}$ \\
\hline Litigation & External & $\begin{array}{l}\text { - Internal control to minimize probability of litigation } \\
\text { - Insurance at levels deemed appropriate by management and common in industry }\end{array}$ \\
\hline Disruptive technologies & External & $\begin{array}{l}\text { - High focus on innovativeness } \\
\text { - Next47 } \\
\text { - Corporate Technology department } \\
\text { - Collaboration with start-ups, leading universities and research institutions }\end{array}$ \\
\hline Currency risks & External & - Hedging strategies \\
\hline Price competition & External & $\begin{array}{l}\text { - Quality of products } \\
\text { - Brand image }\end{array}$ \\
\hline
\end{tabular}

Table 1: Assurance and management controls - an overview.

and policy developments including the U.S. Food and Drug Administration and the European Commission's Health and Consumer Policy Department. Adherence to these regulations and policies is a legal requirement and failing to do so could lead to litigation cases or reputational damages. The company employs several measures for quality improvement and claim prevention. Additionally, the increased use of quality management tool improves the visibility of problem areas and assists in strengthening the root cause and prevention process [4]. Also, well-developed and enforced internal control processes can ensure that Healthineers meets these requirements.

Any company, including Siemens Healthineers, can be subject to litigation. The consequences of these legal disputes or proceedings can be manifold including the payment of fines or damages, criminal or civil sanctions, the disgorgement of profits or even the formal or informal exclusion from tenders or the loss of business permits or licenses. The ramifications can subsequently have a material effect on the company's financial position, cash flows or the results of operation. Precautionary provisions include the strict adherence to laws, regulations and requirements ensured through its internal control system. However, this does not suffice. Additionally, Siemens keeps liability insurance for legal risks at levels which management deems appropriate and is consistent with industry practices [5].

Technology: The industry Siemens Healthineers operates in is characterized by rapid changes and disruptive technologies. To ensure competitiveness, market dominance and going concern, engineering excellence, innovativeness and product and process quality is paramount. To manage these risks, Siemens Healthineers is highly dependent on its human capital. The attraction, retention and development of its human resources is ensured through its human resource management including training and development activities. Its expenditures on research and development activities and the resulting high number of granted patents shows that Siemens
Healthineers places great importance on this aspect. Siemens has established a Corporate Technology department which focuses on highly sophisticated software solutions for all fields that Siemens is active in. This shows that the company has not only recognized the need of its customers to create highly flexible, connected factories and processes but also its need for its own operations. The department is "both a creative driver of disruptive innovations and a partner to the Siemens businesses" [5]. Moreover, the company makes use of open innovations by collaborating with start-ups, leading universities and research institutions to foster an environment of innovation and creativity. To foster its focus on innovativeness and creativity, Siemens has created an autonomous unit in Germany in 2016 that places the partnership with start-ups on an even higher level. The aims of the project, called next 47 , is to further enhance innovativeness and speed up the time-to-market of new products and innovations [4].

Finances: As a globally operating company, Siemens Healthineers is subject to currency and market price risks. Particularly, as a German company conducting a major part of its business in the US, currency fluctuations between the Euro and the US Dollar can be quite problematic. To deal with currency risks, Siemens Healthineers employs a series of hedging strategies [4].

Competition: Additionally, financial risks can stem from the currencies of emerging markets. Competitors located in countries with weaker currencies can produce their products at lower costs. Subsequently, their products can be offered in the market at lower prices. Since the competitive landscape faced by Siemens Healthineers is highly price competitive, this can pose a major problem for the company. However, Siemens Healthineers strategic position focuses rather on product differentiation, quality and innovativeness than on price leadership. Additionally, the company's image and brand recognition helps to remain competitive (Table 1). 


\section{Conclusion}

As any company, Siemens Healthineers faces a vast number of risks relating to both, the internal and the external environment. Appropriate risk management practices are necessary to ensure that these risks do not impact the financial and operational performance of the company considerably. Generally, Siemens Healthineers bases its enterprise risk management approach on the COSO ERM integrated framework. Here, risks and opportunities are identified and managed on a net risk approach thus residual risks are evaluated after appropriate risk management practices have been employed.

\section{References}

1. Siemens (2017) Healthcare/company profile/together.

2. Forbes (2016) Companies/Siemens.
3. Kaeser J (2015) Speech at the Annual Shareholders' Meeting of Siemens AG.

4. Siemens (2016) Annual Report Siemens AG.

5. Siemens (2016) Healthcare/ Company Profile.

6. Siemens (2017) Jobs and Careers.

7. Judge T, Thoresen C, Bono J, Patton G (2001) The job satisfaction-job performance relationship: a qualitative and quantitative review. Psychol Bull 127: $376-407$.

8. Haar J, Russo M, Sune A, Malaterre AO (2014) Outcomes of work-life balance on job satisfaction, life satisfaction and mental health: A study across seven cultures. J Vocat Behav 85: 361-373.

9. Siemens (2017) Products and Services.

10. Siemens (2017) History.

11. Cooper CL (1980) Culture's Consequences: International differences in work related values. Sage Publications, Beverly Hils, London. 